\title{
"I Prefer an Everyday Style and Dislike Big Food Fighters": Integrating Foodshow into Everyday Life
}

\author{
Zhixuan Zhou \\ School of Information Sciences \\ University of Illinois at Urbana-Champaign \\ $\underline{\text { zz78@illinois.edu }}$ \\ Xianghua Ding, Xinru Tang \\ School of Computer Science \\ Fudan University \\ \{dingx, 15300160005\}@fudan.edu.cn
}

\author{
Yunan Chen \\ Informatics \\ University of California, Irvine \\ yunanc@ics.uci.edu
}

\begin{abstract}
In this paper, we examine a genre of User Generated Videos (UGV) centering around food which we term "foodshow". While Korean mukbang ${ }^{1}$ features streamers eat large quantities of food, foodshow features mundane activities in life. Toward understanding unique watching practices of foodshow given its difference from mukbang, we interviewed 12 foodshow viewers in China, uncovering active and life-oriented watching of foodshow - viewers actively choose and watch foodshow which walks a fine line between authenticity and attractiveness, reflecting everyday existence and involving moderate performance at the same time. With these unique features, foodshow watching is integrated into viewers' daily life, and helps in eating, sleeping, and emotional adjustment, in addition to entertainment. Based on the findings, we suggest design implications for healthier and more beneficial foodshow.
\end{abstract}

\section{Introduction}

The recent development of online video sharing platforms such as YouTube ${ }^{2}$, Bilibili ${ }^{3}$ and Douyin ${ }^{4}$ has lowered the bar for video content production, and led to the prevalence of UGV [1]. Professionally Produced Shows (PPS), such as reality shows, are designed and shot by professionals. UGV - either in the form of live-streaming or pre-recorded videos - are shot by end users and regarded as an important supplement to PPS $[2,3,1,4,5]$.

In this paper, we focus on a particular genre of UGV - foodshow in China. The earlier form of foodshow (a.k.a. mukbang) originated in South Korea around 2010 [6], and featured streamers (a.k.a. "big food fighters")

\footnotetext{
${ }^{1}$ Mukbang is mashup of two Korean words: "eating" (meokneun) and "broadcast" (bangsong).

${ }^{2}$ https: / / www . youtube. com

${ }^{3}$ https://www.bilibili.com, a Chinese video sharing application for animation, comics and games. It is nicknamed "B site".

${ }^{4}$ https : / / www . douyin.com, a Chinese application for short video sharing and live-streaming, known internationally as TikTok.
}

eating huge amount of food. Some streamers had millions of followers on their channels simply by eating and talking in front of the camera [7]. Chinese streamers started streaming foodshow around 2015, and included even more elements centering around eating and food than mukbang. Not limited to binge eating and chatting, they also cooked dishes, visited restaurants, and talked about diverse food culture, enriching the concept and extending the boundary of mukbang. Foodshow has captured much attention online in China. Many content providers have over 1 million followers on video sharing platforms. Due to its popularity, many online sellers stream foodshow as a way to promote selling. For example, foodshow had 1.6 billion visits in 2018 on Taobao $^{5}$ [8] alone. While first cast in the form of live-streaming, today more foodshow is produced and watched in pre-recorded short-form videos, in which streamers edit the lengthy process of cooking and eating, and only present the most exciting parts. This aligns well with the trend that short videos are currently drawing more attention than live streams in the online video industry [9]. Some streamers, who started their careers and became Internet celebrities by live-streaming, have transitioned to pre-recorded videos [10], and only livestream for real-time interaction with their followers. We term streamers who produce pre-recorded videos "content providers".

There has been work on mukbang $[11,12,6]$, especially those with exaggerated performance and visual effects [13], mainly focusing on how to engage viewers. Foodshow contains more mundane and diverse elements than mukbang, and could potentially play more diverse roles than mukbang in people's daily life. While foodshow receives far less attention from the HCI community than mukbang, empirical study on it can potentially lead to a deeper understanding of everyday use of mundane food media and its practical roles. Toward understanding unique watching practices around pre-recorded foodshow, which we defined as a genre of

\footnotetext{
${ }^{5}$ https://www.taobao.com, a Chinese online shopping website.
} 
UGV featuring diverse activities around food, such as eating and cooking, we proposed the following research questions:

RQ1: How do viewers choose foodshow to watch? RQ2: How do viewers watch foodshow in daily life?

We conducted an interview study with 12 regular foodshow viewers in China. Based on the findings, we reflect on characteristics and roles of foodshow, in order to fulfill its value for viewers' life. Our paper contributes an empirical study of foodshow watching from the perspective of Chinese viewers, demonstrates practical roles of foodshow, and suggests design implications for better foodshow.

\section{Related Work}

\subsection{User Generated Videos}

Production, sharing and watching of UGV are found meaningful to various aspects of people's life. Generation of online content is related to psychological empowerment of users [4]. Friendship can also be fostered through video production: video exchange practices and the surrounding discourse may help create local networks by enabling affective exchanges [14]. On the practical level, UGV can be regarded as an additional source of information, helping people decide where to travel [5] and what to buy [15]. Such information is not only gained through streams, but also via peripheral media such as comments [16]. UGV have also been leveraged to support educational purposes, e.g., they are regarded as innovative learning resources [17].

Despite the benefits mentioned above, impact of $\mathrm{UGV}$ is not always positive. It has been found that users do not always generate healthy content or supportive networks [18]. For instance, recent research shows that user-generated content advocating harm (e.g., pro-eating-disorder, pro-self-harm and pro-suicide materials) offers potential risk for Internet users [19]. The negative impact of UGV has also been observed in Korean mukbang - streamers use binge eating to attract attention, and viewers blindly imitate their behavior, raising health concerns. The South Korean government has actively planned a crackdown on binge-eating broadcasts to control the rising obesity rate [20].

Live streaming in China has been extensively studied. For example, Lu et al. [21] uncovered live streaming practices in China, revealing how content, reward systems and fan group chat engaged viewers. Chinese streamers also used livestreaming to showcase and promote ICH (Intangible Cultural Heritage) activities [22]. During COVID-19, K-12 and college teachers in China utilized live streaming to deliver online teaching for better student engagement [23]. While food-related UGV in China receives less attention from the HCI community, we conduct an exploratory study on foodshow watching practices to enrich this literature.

\subsection{Food Media}

With the integration of social media into people's life, people interested in food and media are able to rely on social media to post and consume food content, forming a digital food community [24]. It is found that food is central and framed positively in a majority of adolescents' Instagram images [25].

Digital food content presented on social media can largely reflect individual eating practices, as well as particular social and cultural context. [26] uses "food selfies" posted on social media as a means of exploring changing spatio-temporal characteristics of eating practices. The prevalence of Korean mukbang can be partly attributed to the one-person household phenomenon in Korea [11]. Korean viewers watch it as a way to accompany eating [6] and relieve loneliness [12].

A recent paper [13] studies motivations and practices of mukbang viewers worldwide, which is the most related work to ours. They identify mukbang watching as a mealtime companion and a leisure activity. People watch mukbang for attachment to mukbangers, vicarious pleasure, and performance of excessive eating. However, this work little touched on the everydayness of mukbang and its roles in daily life.

In this paper, we will explore foodshow, similarly eating-related but more diverse UGV than mukbang and other food media. By situating it in Chinese social and cultural context, which puts an emphasize on eating, we will examine how Chinese people watch foodshow, and how foodshow plays a role in their life.

\subsection{Eating- and Health- Related Technologies}

Eating plays important roles in human life. Not only do people consume food to get nutrition, but also to enjoy the relaxing and pleasurable process of eating. Moreover, eating plays important socio-cultural roles beyond its impact on individuals. It has been shaped by, while at the same time shapes, diverse culture [27].

In the HCI field, there is a rich literature on Human-Food Interaction (HFI), seeking to improve eating and cooking experience through technology [28]. For instance, applications are designed to assist people in making effective decisions on what to eat [29]. Technologies such as human activity recognition software, sensors and augmented reality (AR) have 
been explored to help people prepare food [30], and learn to cook new dishes [31]. Living Cookbook allows individuals to record and share the process of preparing meals, during which social bonds and intimate relationships can be established and enhanced [32].

Eating is closely related to health, and much work has been done to support healthy eating. Individuals suffering from eating disorders can receive Cognitive Behavioral Therapy (CBT) via a mobile video app [33], which improves service reach of traditional clinical treatment. Social intervention and support for healthier eating are also explored, e.g., mobile phone applications [34] and Internet weight loss communities [35] are shown helpful for weigh loss. While many members of online weight loss communities choose to take an active role in providing social support, even those who choose a more passive role can still get informational and emotional benefits [36]. Eating can also be helpful to mental health. Particular food objects are associated with the relief of distress, and can be manipulated to modify or change emotional states and feelings [37].

While much work has been done on building computing technologies to enhance eating experience, support healthy eating, and address eating-related health issues, we want to see if foodshow viewing can also play certain roles, considering its intrinsic relationship with practical eating. Roles of foodshow in other fundamental aspects of life are also worth exploring, which is lacking in existing research of mukbang.

\section{Method}

To understand how foodshow was watched in people's daily life, we conducted a qualitative study. In prior observation, we searched for foodshow of famous content providers such as Mizijun on Douyin, Weibo and Bilibili, which were main platforms for foodshow sharing and watching. Thanks to recommendation systems of these platforms, we were recommended more foodshow videos, as well as food-related PPS such as variety shows. We observed genres (e.g., pre-recorded foodshow, live foodshow, foodshow PPS) and themes (e.g., eating, cooking, chatting, visiting restaurant) of the videos to get a sense of this landscape. We also joined $\mathrm{QQ}^{6}$ chat groups established by foodshow lovers to observe how they shared and talked about foodshow videos, which allowed us to build rapport with them, and ask more focused, informed questions in interviews.

We started recruitment by posting recruitment flyers in these QQ chat groups and our WeChat ${ }^{7}$ Moments

\footnotetext{
${ }^{6}$ https : / / im. qq. com, a mobile communication application in China.

${ }^{7}$ https://www. wechat.com/en, a mobile communication application in China.
}

(where users can see friends' posts). To first get a brief understanding of foodshow viewers, we started interviews with our acquaintances and chat group members. We then let these participants introduce other foodshow viewers they knew to us. Recruitment ended when we believed themes in analysis reached saturation. In the end, we had 12 foodshow viewers for the study. Information about the participants is provided in Table 1. All participants were under 30, and were mainly university students (10/12). This might be explained by the demographics of foodshow audience - young people accounted for a large proportion of foodshow viewers [8]. Similarly, in the research of mukbang [13], 10/15 participants were students. In the discussion, we call for customizing foodshow to benefit other age groups.

Our interviews were semi-structured, and were conducted either in person or via audio calls on WeChat from May to July in 2019. The interviews lasted for 40-90 minutes. Interview questions covered participants' initial foodshow watching experience, how they found and chose foodshow to watch, specific cases of when they watched what foodshow, and how foodshow played a role in their life. The interviews were conducted in Mandarin, audio-recorded, and later transcribed for data analysis. Participants were provided with a $50 \mathrm{CNY}$ honorarium for their time. Our study was reviewed and approved by the Research Department of the home university of authors.

We started the analysis while the data was being collected. Two Mandarin-speaking authors coded the transcriptions independently, and met in person to discuss and reach a consensus. Through open and axial coding, themes started to merge, and brought us back to the transcriptions to find more data. We used XMind ${ }^{8}$ to organize quotes into a hierarchy of themes. After several iterations of analysis, we arrived at the findings and implications. In this paper, we will use translated, anonymized quotes to illustrate our points.

\section{Findings}

Our participants have watched foodshow for at least half a year. Some have watched it for a longer time, up to more than 6 years (P12). Some started watching Korean mukbang even before Chinese streamers started their foodshow careers. The participants watched foodshow at least three times a week, except for P10 who only watched it when she could not fall asleep (1-2 times a week), and would watch it for more than 1 hour each time. Some heavy viewers, like P2, watched it on a more frequent basis: "I watch foodshow from 11pm till I go

\footnotetext{
${ }^{8}$ https : / /www. xmind. net, a mind mapping tool.
} 


\begin{tabular}{|c|c|c|c|c|c|c|c|c|}
\hline$I D$ & Gender & Age & Occupation & Years of Watching & Days per Week & Content & Main Platform(s) & When to Watch \\
\hline $\mathrm{P} 1$ & $\mathrm{~F}$ & 20 & Undergraduate student & $2+$ & $4-5$ & Cooking; Eating & Bilibili & At night \\
\hline $\mathrm{P} 2$ & $\mathrm{~F}$ & 20 & Undergraduate student & $2+$ & 7 & Eating & Bilibili; Weibo & At night \\
\hline P3 & M & 21 & Undergraduate student & $2+$ & 7 & Eating & Bilibili & At night \\
\hline $\mathrm{P} 4$ & $\mathrm{~F}$ & 25 & Freelancer & $1-$ & $3-4$ & Eating & Weibo & At night \\
\hline P5 & $\mathrm{F}$ & 20 & Undergraduate student & $1-$ & 3 & Eating & Weibo & All day \\
\hline P6 & M & 20 & Undergraduate student & 2 & 7 & Cooking; Eating & Bilibili & At noon; At night \\
\hline P7 & $\mathrm{F}$ & 20 & Undergraduate student & $4+$ & Flexible & Cooking; Eating & Bilibili; YouTube & At night \\
\hline P8 & $\mathrm{F}$ & 23 & Programmer & $2+$ & 3 & Cooking; Eating & Bilibili & At night \\
\hline P9 & $\mathrm{F}$ & 20 & Undergraduate student & $3+$ & $3-4$ & Cooking; Eating & Bilibili; Weibo & At night \\
\hline P10 & $\mathrm{F}$ & 20 & Undergraduate student & $2+$ & $1-2$ & Eating & Bilibili & At night \\
\hline $\mathrm{P} 11$ & $\mathrm{~F}$ & 26 & Graduate student & 2 & 7 & Cooking; Eating & Douyin & All day except night \\
\hline P12 & M & 25 & Graduate student & $6+$ & 7 & Eating & Bilibili & When eating \\
\hline
\end{tabular}

Table 1. Basic information of study participants (foodshow viewers).

to sleep, around one to two hours, nearly every day." P3, P6, P11 and P12 also watched foodshow on a daily basis. Our participants all watched foodshow using their smartphones. Generally, they were quite positive about foodshow, indicating that it brought them pleasure and had practical value. For all of them, foodshow watching has become an integral component in life.

Several participants compared foodshow to food-related PPS, which they consumed for different purposes. While longer chunks of time such as mealtime were used to watch higher-quality PPS for entertainment, foodshow in pre-recorded videos was watched during shorter time periods throughout the day for fun and practical purposes.

\subsection{Active Selection and Watching of Foodshow (RQ1)}

4.1.1. From Algorithmic Recommendation to Active Following The majority of participants started watching foodshow from random recommendation of the platforms. However, they ended up watching followed content providers whose styles matched their taste instead of passively following recommendations.

Viewers followed content providers for their special characteristics, skills and charisma. For example, P3 only watched content providers who he thought presented good performance and humor. He explained,

"I mostly watch foodshow shot by content providers I followed... Sometimes the platform would recommend other content providers to me and I may watch them for a while, but overall I stick to the three guys and watch nearly every video of them. Their shows are just more fun, with more performance and humor."

P9 preferred content providers who ate elegantly and enjoyed the food, and disliked fast eating as a challenge.

As we can see, over time, viewers' loyalty to content providers whose style suited their tastes played a larger role than recommendations in deciding what to watch. They may still click on recommended content, especially when running out of videos by their favorite content providers, but their viewing became more active and content provider-oriented. According to our participants, despite the fact that content providers had a certain chance to be seen as a result of decentralized policy of recommendation systems, only those with attractiveness and certain styles could stand out.

4.1.2. Short Foodshow is Favored Our participants preferred foodshow in pre-recorded short-form videos, in which content providers ate fast, so that viewers could always keep attentive [38] and benefit from it. None of them reported watching foodshow live streams, since they were perceived as too long or did not match their schedule. P1 preferred fast-paced videos in which content providers did not talk much, instead of live shows in which streamers ate slowly. P8 also complained about the lengthiness and boredom of live shows, which were "just eating from beginning to end".

P6 explained the advantage of short videos, and described how lengthy foodshow was separated:

"I like shorter videos. Lengthy ones would tire people and drive them away. Shows around 20 minutes are the best for me. If it exceeds that time, the content provider would remind the audience to be patient at the beginning of the show, or just edit it into two separate videos."

4.1.3. Watching Foodshow Echoing with Daily Life Our participants liked foodshow close to their life in terms of food, content providers, and personal experiences. Such shows were consistent with their life experience, which they could identify with.

Common Food is Good Enough. All the participants loved to watch food which was familiar to them and consumed on a daily basis, such as street food and 
home-cooked meals. P5 described her favorite content provider who mainly ate commonplace food:

"She eats local food and visits restaurants... She has a special preference for 'fly restaurants' " and street food."

Food in such foodshow was so common that viewers had easy access to it. Thus it was more likely to evoke a response from viewers, as shown in this quote by P11:

"The dishes are cooked with basic condiments. But they're the ones you really want to eat by yourself. He once cooked Coca-Cola Chicken Wings and Red Date Cake, which were my mum's favorite. I was really impressed, and shared the video immediately with her."

Approachable Content Providers. Content providers did not have to be stunning. Many popular content providers were of above-average appearance, as P2 said, "Content providers don't have to be physically attractive to be popular. From my observation, they're seldom packaged by entertainment companies."

Aside from approachable appearance, content providers made themselves closer to audience by willingly interacting with them. For example, P12's favorite content provider had replied to him several times, making him feel warm:

"If I ask questions about recipes in comments, peer viewers would reply to me... Sometimes the content provider answered my questions himself. He doesn't regard himself as a superstar, and is very accessible."

Similarly, P5's favorite content provider would choose restaurants based on viewers' recommendations. She also gathered her fans into a WeChat group, making them feel closer in the online community. Such practices added to authenticity and everydayness of foodshow.

All About Daily Life. Personal life of content providers was presented in their shows without careful pre-planning or editing, making the shows more authentic. Our participants repeatedly mentioned these moments, e.g., a content provider traveling with his family (P6). After watching shows for some time, viewers got familiar with their life, and developed a sense of attachment to the content providers. For example, P9 regarded her favored content provider as a close friend, and told us many details about her:

"Having watched her foodshow for so long, I regard her as my friend... She majors in art. She can speak German. She's going to UK for graduate study. She's rough and authentic. She has a fatty younger brother."

Moreover, viewers often chose to watch foodshow which was close to their own life experiences, such as food and content providers from their hometowns. For example, as a Sichuan local, P5 only watched foodshow by a Chengdu content provider featuring local food:

\footnotetext{
${ }^{9}$ Restaurants with simple decoration and relatively cheap prices that serve delicious dishes.
}

"Foodshow of Sichuan food is most attractive. I eat Sichuan food mostly, and Hunan recipes occasionally. Spicy food is my favorite. I never like light dishes!"'

According to P5, she felt pride in and a sense of belonging to her hometown and its local delicacies, which partly explained her loyalty to this content provider and her foodshow featuring Sichuan food. Similarly, P9 who grew up near the sea had a preference for foodshow featuring seafood.

With an abundance of foodshow available online, it was possible for people with different backgrounds and tastes to find foodshow that could strike a chord in them. Flaws are Tolerable and Even Liked. Interestingly, instead of having negative effects on participants' viewing experience, mistakes or defects in foodshow increased its attractiveness, since they made the shows more real, and offered the opportunity for friendly interaction and the forming of an engaged community. In such cases, viewers would kindly show care for the content providers. P6 talked about such a case:

"One time, when the content provider was making Tomahawk Ribeye Steak, he forgot to remove the plastic wrap. In later foodshow, viewers would remind him to remove the wrap through Danmaku ${ }^{10}$."

However, not all mistakes were tolerable. For instance, making inappropriate comments annoyed viewers with knowledge on the given topic, as P10 said: "Her video shot in Wuhan really annoyed me. She didn't fully prepare for the show. She knew very little about Wuhan and local food, and her comments were never right. I was damn irritated as a local."

4.1.4. Watching Foodshow Beyond Daily Life While people chose to watch foodshow closely resembling daily life, these shows could not be simple copies of life. Instead, they must include performance and exaggeration, which afforded the "show" feature of foodshow. We identify the following ways in which content providers made foodshow attractive to watch.

Eating Much, But not Too Much. Eating more than ordinary people did was the easiest way to attract viewers' attention. Several participants mentioned Mizijun, a popular content provider who ate a lot in her foodshow, though not as much as "big food fighters" in mukbang did, who kept eating to the point that it had a negative effect on their health $[39,6]$.

They acknowledged occasionally watching big food fighters out of curiosity, but not on a regular basis. After all, most participants preferred watching healthier and more pleasurable eating on a daily basis. For

\footnotetext{
${ }^{10}$ Danmaku enables audience to post comments onto the videos, which are visible to other audience members.
} 
example, although P2 considered eating more than ordinary people did as what made one "qualified" as a content provider, to her, what was more important was that content providers should really enjoy the food and stop eating when they were full, instead of forcing themselves to eat for eye-catching effects. P2 said:

"I prefer an everyday style, and dislike big food fighters. I feel that they don't want to eat that much, but force themselves to do so. This makes me lose my appetite. Who on earth would eat that much food? It's just unreal and not necessary at all."

Content Providers with Great Skills and Charisma. Viewers were impressed by content providers with skills or capabilities. For example, P5 described one content provider as a master of many skills:

"She can do anything: cooking, planting vegetables, cutting firewoods, making furniture... She recently went to Vietnam to present Chinese culture to the imperial household... She sells things made by herself online."

Good performance and video-editing could further add to attractiveness of foodshow. Several participants were impressed by content providers' humor and jokes. P6 admired the masterful editing of certain content providers' videos as well as their dramatic flair:

"I watch foodshow because I find the video-editing interesting... He's really good at dramatizing common things. For example, he actually buys something, but he pretends to pull it out from nowhere, like a magic show."

While adding exaggerated elements to foodshow could attract viewers, too much was exhausting. After all, food-related elements, e.g., cooking and eating, were the most important features. P7 once loved an American YouTuber's performance, but got tired of it later:

"Though the American YouTuber is funny, I don't watch his shows as often now. The dishes he cooks are really strange. He's just spoofing, and doesn't mean to cook." Thus to retain viewers, content providers should walk a fine line between attractiveness and authenticity.

\subsection{Integration of Foodshow in Life (RQ2)}

In this section, we will illustrate how people leverage foodshow watching to benefit life, in terms of eating, sleeping and emotional adjustment.

4.2.1. Foodshow Watching and Eating Eating is an everyday necessity, and foodshow was commonly and actively used by our participants to serve their needs and desires around eating.

Enhancing Eating Experience. Sometimes, foodshow was watched to enhance eating experience, especially when what viewers ate was not appetizing. P12, who was the only participant exclusively watching foodshow during meals, reported that he ate better when foodshow served as the background to his meals:

"Watching foodshow stimulates my appetite. I mainly eat in campus canteens, where food isn't very delicious. Watching foodshow makes my eating experience much better. I'm just willing to eat more."

Similarly, P1 watched foodshow when she was on a diet, and her diet meals did not taste very good. She acknowledged that foodshow made her food tastier.

Vicariously Satisfying Desires. Foodshow watching was leveraged to satisfy desires for food that was not affordable or easily available. Through watching foodshow, such desires could be vicariously fulfilled. For example, P7 was satisfied by watching content providers eating food that she could not afford:

"I still remember the video where she ate a whole bucket of king crabs and other seafood. I'll never afford that, but watching her eat is more than satisfying."

More often, foodshow watching was triggered by hunger and used for diet control by virtually fulfilling viewers' desire for food. P2 was such a case:

"The content provider eats a lot of rice. I don't want to eat that much by myself, so I just watch him eating... Watching others eat can relieve my sense of hunger, and I just don't have the desire to eat anymore. In this way, I don't need to worry about gaining weight."

When viewers found others also watch foodshow for diet control, they were encouraged to persist. P3 noted, "Many people also indicate watching foodshow to lose weight through Danmaku. They're like, 'I don't feel hungry when watching this.' I just find many peers here. It's harder for me to persist if I'm alone."

Such community support and peer encouragement for weight loss found in foodshow watching is very similar to that found in online weight loss communities [35].

Providing Information for Eating and Cooking. While UGV have been found helpful in providing practical information for travelling [5] and shopping [15], our participants also benefited from information provided by foodshow for eating and cooking. For example, it helped participants decide what to eat. P1 often considered content providers' recommendations when deciding on restaurants or food:

"I would try restaurants recommended by her. She once recommended Chuanchuan (remix of 'skewered food' and hot pot) and roasted meat. I went to the restaurants following her recommendation. Really delicious!"

P6 and P10 had similar experiences of trying food recommended by content providers.

However, P1 reported her negative experience of eating based on content providers' recommendation, and mimicking their eating behavior: 
"I'm attracted by delicious food in the shows and want to buy all of it. I thought I could eat them all when ordering, but I overestimated my stomach. Often I wound up too full, which was bad for my health."

Such binge eating behavior triggered by foodshow watching caused waste of food, and had negative effect on health. She suggested the platforms take measures to prevent binge eating and blind imitation.

Learning to cook was yet another motivation for viewers to watch foodshow. P11 was such an example:

"I watch much foodshow featuring cooking. The process of adding condiments is detailed and a close-up shot is given to dishes in the end... Cooking gives me pleasure, and I learn how to cook through foodshow."

She also discussed foodshow with her boyfriend. Thus foodshow not only helped her learn cooking, but also motivated her interaction with people in real life.

4.2.2. Foodshow Watching and Sleeping Our participants commonly watched foodshow at night. A closer examination revealed that foodshow fulfilled several sleep-related needs, and was fitting for this time. Relaxing Pre-bed Entertainment. Some participants watched foodshow before sleep because it was the most relaxing time of the day. They regarded foodshow watching as an easy and flexible entertainment which did not require any thinking and could perfectly fill the insufficient time before bed (P2, P9, P10). P2 said,

"I watch foodshow usually when I'm really tired. I just don't need to use my brain when watching foodshow."

The short duration of pre-recorded videos also helped viewers avoid being indulgent and watching late into night, while foodshow live streams and lengthy PPS did not have this advantage, as indicated by $\mathrm{P} 9$,

"Variety shows are often more than an hour. If I watch variety shows before sleep, it'll be too late when I finish watching them. Foodshow is much shorter, and I can stop watching it whenever I want to."

Sleeping Better after Watching Foodshow. Some participants utilized foodshow to help them fall asleep (P2, P3, P10). P10 fell asleep sooner by watching foodshow and thinking about what to eat the next day.

P2 utilized the ASMR (autonomous sensory meridian response) effect of foodshow to help her fall asleep. Simply by listening to the chewing sound in foodshow, she was able to sleep better:

"My roommate recommended me ASMR-related foodshow. I tried it, and it worked! I slept better than before. I don't listen to chewing sound on a daily basis, but I do when I have difficulty falling asleep."

A Rescue for Pre-bed Hunger. Some participants attributed watching foodshow before sleep to the fact that it was natural to feel hungry at night, yet they felt obliged to avoid eating at this time (P1, P3, P10). For example, P1 often felt hungry at night, and relieved her sense of hunger by watching others eat. Similarly, P3 watched foodshow only at night to control night eating: "You don't need to eat by yourself. You feel satisfied by just watching others eating... I don't watch foodshow in the day, since I'm free to eat anything whenever hungry."

\subsubsection{Foodshow Watching and Emotional} Adjustment Eating has often been considered as a way to relieve stress [40]. Some of our participants watched foodshow to relieve stress while avoiding the risk of gaining weight. For example, P1 described her work stress and will for binge eating:

"High pressure drives me mad. I'm really busy. I recently worked till 9 or 10 into night. After getting home, I really wanted to binge eat to relieve my stress." Stuck between the choices of binge eating (to relieve stress) and maintaining her diet (to keep body shape), watching foodshow became her best alternative, as it satisfied both needs.

P11 was busy with part-time jobs every day, and watching foodshow on Douyin comforted her a lot:

"Swiping (to the next) videos on Douyin makes me forget my sadness and pressure. I don't think about anything else, just swiping and swiping."

For her, healing elements were not only foodshow itself, but also technical feature of the short video platform.

Similar to what is reported about mukbang in previous work [12], we also found a case (P12) of using foodshow to gain a sense of company and comfort when eating. He recalled how foodshow helped him through the difficult period after he broke up with his girlfriend: "I have to watch videos when eating. Previously, I ate with my girlfriend. After we broke up, I ate alone... Foodshow gave me warmth and company. It's great!"

\section{Discussion}

In the preceding sections, we have illustrated how participants chose short, authentic and attractive foodshow to integrate into their daily practice and fulfill practical purposes. Based on the findings, we will reflect on active, life-oriented watching of foodshow, and practical gratifications provided by foodshow. We will also propose design implications for a healthier and more beneficial foodshow landscape.

\subsection{Active, Life-oriented Foodshow Watching}

As shown in our study, far from being passive receivers of media content, foodshow viewers actively 
seek specific content to satisfy their needs and desires, e.g., using foodshow to fulfill their desire for food, utilizing ASMR effects to help them sleep. Such behavior can be understood as "audience activity" in Uses and Gratifications Theory (UGT) [41], which emphasizes "what do people do with media?" instead of "what do media do to people?" [42]. Audience activity suggests that media use is motivated by needs defined by audience members themselves [43], aligning well with our findings that viewers watch foodshow to fulfill their practical needs. They actively seek for physical gratifications, including relief of hunger, weight control, better sleep, vicarious satisfaction of inaccessible food, and enhanced eating experience; they also actively seek for mental gratifications, such as easy entertainment, comfort and company, and relief of stress. It is worth noticing that although UGV content has a certain chance to be seen on video sharing platforms, only content providers with certain styles or charisma are favored, either showing sense of humor, or carefully editing video content. Thus content providers have to take an effort to be more attractive to the active audience.

Our participants watch foodshow for practical life purposes, instead of mere entertainment. Thus we consider foodshow watching as life-oriented, in addition to active. The unique watching practices around foodshow are determined by its intrinsic characteristics. Compared to Korean mukbang which is mostly binge eating, foodshow covers a wider range of elements which are close to life, such as cooking food, traveling around to seek local food, etc. Compared to food-related PPS, foodshow walks a fine line between being creatively interesting, and not being excessive or inauthentic, echoing well with viewers' daily life. Such "everydayness" of foodshow is consistent with prior research on live streaming [44], while provides more practical value for daily life. In addition, our participants prefer pre-recorded foodshow videos to live-streaming, as short videos are more flexible and could be an ideal time-filler. With its diverse themes, combination of authenticity and attractiveness, and short duration and flexibility supported by the form of pre-recorded videos, foodshow is used by our participants to fulfill practical needs. Since foodshow watching is life-oriented, too much exaggeration will be regarded as "unnecessary and disgusting". Food and life support should always be the main themes.

Regarding life support, foodshow might provide broader functions than eating-related technologies, many of which only serve one specific need (e.g., guiding cooking [30] or diet control [34]). Produced by different people and thus taking on various themes and styles, foodshow is more multi-faceted and diverse, and might satisfy more practical needs in an on-demand manner. With this in mind, we suggest a function-based recommendation of foodshow for viewers with different needs. For example, after users choose their needs, e.g., sleep help, platforms can recommend ASMR-related foodshow to them. AI techniques can be leveraged to tag each foodshow video with roles it can play.

\subsection{Foodshow in China}

Eating and food mean a lot to Chinese people [45]. Chinese people love to talk about eating and food more than other topics, and greet others with "have you eaten already?" instead of "how are you?" [46]. In China, food serves various socio-cultural functions, including representing social status (e.g., expensive food is used to represent wealth), celebrating important events (e.g., rice dumplings are eaten for the Dragon Boat Festival) and serving as symbols (e.g., peanuts, also known as the longevity fruit, mean longevity) [47]. Food is also used to treat and prevent diseases based on Traditional Chinese Medicine [48]. While previous study on live streaming in China focuses on ICH [22], online education [23], etc., we contributes an exploratory study of everyday foodshow watching practices in China.

We find different motives of Chinese viewers for watching foodshow compared to Korean viewers. The prevalence of Korean mukbang can be attributed to the one-person household phenomenon [11], and Korean viewers watch it as a way to accompany eating [6] and relieve loneliness [12]. Our research uncovers more motives of Chinese viewers for watching foodshow, such as vicariously satisfying desires and helping sleep.

\subsection{Designing for Healthier and More Beneficial Foodshow}

One barrier for promoting healthy eating might be set by binge eating behavior of content providers. It is known that Korean mukbang featuring big food fighters may negatively affect viewers' health $[49,20]$. Some participants in our study also report their over-eating behavior caused by foodshow featuring content providers eat large quantities of food. Though content providers have other options to make foodshow fascinating such as presenting performance and conveying rich culture, those without many skills may try to attract viewers with exaggerated behaviors such as excessive eating. Some video sharing platforms often promote and recommend such content, to attract new foodshow viewers and bring them profits. As shown in our study, when foodshow watching becomes a part of viewers' everyday routines, they no longer favor overly exaggerated content, which is described by them as 
"disgusting if watched too much". Instead, they turn to foodshow featuring pleasurable and healthy eating behavior. Thus recommending healthier content may not only retain the regular users, but also create a more beneficial foodshow landscape for them. At a technical level, platforms could detect binge eating behavior in foodshow and warn viewers about potential health risks, in addition to stopping promoting such content.

There is no report about overuse of foodshow in our data. All our participants watched foodshow only in leisure time, and explicitly stated that foodshow watching itself has no negative impact on their life and studying (many of them were university students). However, from a critical perspective, one may argue that prolonged late-night use of foodshow and cellphone can happen in people who are indulgent in attractive content, and is not good for their health. This can negatively affect sleep, instead of helping sleep and relaxing mind. We recommend designers of video platforms put notifications on the videos, in order to nudge and prevent viewers from watching for too long.

In addition, foodshow audience is limited to young people in our data: all our participants are under 30 years old. While some features of participants are unique to young people especially university students, e.g., seldom cooking, and eating in canteens, other features are also present in other age groups, e.g., having little free time, and suffering from work pressure. Future research could examine the demographic distribution of foodshow viewers, and the reason why certain demographic groups are less interested in foodshow, towards making it more widely adopted.

\section{Conclusion}

We present a study of foodshow which is a variant and expansion of mukbang. Foodshow walks a fine line between authenticity and attractiveness. Combined with its short duration and on-demand feature, foodshow watching could be integrated into viewers' life for practical purposes in terms of eating, sleeping and emotional adjustment, extending the role of mukbang and UGV. To fulfill its potential of providing practical gratifications and health benefits, we reflect on active, life-oriented watching of foodshow, situate foodshow watching in the Chinese context, and suggest design implications for healthier and more beneficial foodshow.

\section{References}

[1] P. Berthon, L. Pitt, J. Kietzmann, and I. P. McCarthy, "Cgip: Managing consumer-generated intellectual property," California Management Review. 57 (4): 43-62, 2015.
[2] M. Hu, M. Zhang, and Y. Wang, "Why do audiences choose to keep watching on live video streaming platforms? an explanation of dual identification framework," Computers in Human Behavior, Volume 75, Pages 594-606, 2017.

[3] S. L. Anderson, "Watching people is not a game: Interactive online corporeality, twitch.tv and videogame streams," The international journal of computer game research, volume 17, issue 1, 2017.

[4] L. Leung, "User-generated content on the internet: an examination of gratifications, civic engagement and psychological empowerment," New Media \& Society, 2009.

[5] C. Cox, S. Burgess, C. Sellitto, and J. Buultjens, "The role of user-generated content in tourists' travel planning behavior," Journal of Hospitality Marketing \& Management, Volume 18, Issue 8: E-Business and Hospitality Management, 2009.

[6] S.-K. Hong and S. Park, "Internet Mukbang (Foodcasting) in South Korea ," Ilana Elea and Lothar Mikos (Eds.) Young \& Creative, 2017.

[7] M. Jaureguilorda, "Mukbang: Why Millions of People Sit in front of Computers and Watch Others Eating?." https: / /www.bbc.com/zhongwen/simp/ world-48495172, 2019.

[8] D. NEWS, "Taobao Released "Eating Show" Report: Sales Increased by $400 \%$ in Food-related Live Studios." http: / / www. donews.com/news/detail/1/ 3042982 .html, 2019

[9] woshipm, "Short Videos are Ready to Take the Lead!." http: //www.woshipm.com/it/2546986. html, 2019.

[10] Zhihu, "Transformation of Eating Shows: Inspired by Acute Observation of the Video Market." https : // zhuanlan.zhihu.com/p/42074944, 2018.

[11] W.-J. J. Yeung and A. K.-L. Cheung, "Living alone: One-person households in asia," Demographic Research, Volume 32, Pages 1099-1112, 2015.

[12] Y. Kim, Routledge Handbook of Cultural and Creative Industries in Asia, ch. Sell your loneliness: Mukbang culture and multisensorial capitalism in South Korea. London: Routledge, 1st ed., 2018.

[13] L. Anjani, T. Mok, T. Tang, L. Oehlberg, and W. B. Goh, "Why do people watch others eat? an empirical study on the motivations and practices of mukbang viewers," in Proceedings of the 2020 CHI Conference on Human Factors in Computing Systems (CHI'20), ACM, 2020.

[14] P. G. Lange, "Fostering friendship through video production: How youth use youtube to enrich local interaction," in International Communication Association Conference, 2007.

[15] J. E. Lee and B. Watkins, "Youtube vloggers' influence on consumer luxury brand perceptions and intentions," Journal of Business Research, Volume 69, Issue 12, Pages 5753-5760, 2016.

[16] M. LaeeqKhan, "Social media engagement: What motivates user participation and consumption on youtube?," Computers in Human Behavior, Volume 66, Pages 236-247, 2017.

[17] S. C. Burke and S. L. Snyder, "Youtube: An innovative learning resource for college health education courses," International Electronic Journal of Health Education, page 39-46, 2008. 
[18] G. Fergie, K. Hunt, and S. Hilton, "Social media as a space for support: Young adults' perspectives on producing and consuming user-generated content about diabetes and mental health," Social Science \& Medicine, Volume 170, Pages 46-54, 2016.

[19] T. Keipi, A. Oksanen, J. Hawdon, M. Nasi, and P. Rasanen, "Harm-advocating online content and subjective well-being: a cross-national study of new risks faced by youth," Journal of Risk Research, Volume 20, Issue 5, 2017.

[20] K. Park, "South korea to clamp down on binge-eating trend amid obesity fears," The Telegraph, 2018.

[21] Z. Lu, H. Xia, S. Heo, and D. Wigdor, "You watch, you give, and you engage: A study of live streaming practices in china," in Proceedings of the CHI Conference on Human Factors in Computing Systems, pp. 1-13, ACM, 2018.

[22] Z. Lu, M. Annett, M. Fan, and D. Wigdor, "“i feel it is my responsibility to stream": Streaming and engaging with intangible cultural heritage through livestreaming," in Proceedings of the 2019 CHI Conference on Human Factors in Computing Systems, ACM, 2019.

[23] X. Chen, S. Chen, X. Wang, and Y. Huang, ““i was afraid, but now i enjoy being a streamer!": Understanding the challenges and prospects of using live video streaming for online education," in Proceedings of the ACM on Human-Computer Interaction, pp. 1-32, ACM, 2020.

[24] S. Rousseau, "Food and social media: You are what you tweet," Rowman Altamira, 2012.

[25] C. Holmberg, J. E. Chaplin, T. Hillman, and C. Berg, "Adolescents' presentation of food in social media: An explorative study," Appetite, Volume 99, Pages 121-129, 2016.

[26] B. Middha, "Everyday digital engagements: using food selfies on facebook to explore eating practices," Journal of Communication Research and Practice, 2018.

[27] D. Lupton, "Consuming geographies: We are where we eat," Routledge, New York, 1997.

[28] A. Grimes and R. Harper, "Celebratory technology: New directions for food research in hci," in Proceedings of the 2017 CHI Conference on Human Factors in Computing Systems, pp. 6960-6972, ACM, 2017.

[29] M. Svensson, K. Hook, J. Laaksolahti, and A. Waern, "Social navigation of food recipes," in Proceedings of the 2001 CHI Conference on Human Factors in Computing Systems, pp. 341-348, ACM, 2001.

[30] Y. Nakauchi, T. Fukuda, K. Noguchi, and T. Matsubara, "Intelligent kitchen: cooking support by lcd and mobile robot with ic-labeled objects," in Proc. IROS, pp. 1911-1916, IEEE, 2005.

[31] W. Ju, R. Hurwitz, T. Judd, and B. Lee, "Counteractive: an interactive cookbook for the kitchen counter," in Proceedings of the 2001 CHI Conference on Human Factors in Computing Systems, pp. 269-270, ACM, 2001.

[32] L. Terrenghi, O. Hilliges, and A. Butz, "Kitchen stories: sharing recipes with the living cookbook," Personal and Ubiquitous Computing, 11, 409-414, 2007.

[33] N. Abrahamsson, L. Ahlund, E. Ahrin, and S. Alfonsson, "Video-based CBT-E improves eating patterns in obese patients with eating disorder: A single case multiple baseline study," Journal of Behavior Therapy and Experimental Psychiatry, Volume 61, Pages 104-112, 2018.
[34] G. F. Mateo, E. Granado-Font, C. Ferre-Grau, and X. Montana-Carreras, "Mobile phone apps to promote weight loss and increase physical activity: A systematic review and meta-analysis," Journal of Medical Internet Research, Vol 17, No 11, 2015.

[35] K. O. Hwang, A. J. Ottenbacher, A. P. Green, M. R. Cannon-Diehl, O. Richardson, E. V. Bernstam, and E. J. Thomas, "Social support in an internet weight loss community," International Journal of Medical Informatics, Volume 79, Issue 1, Pages 5-13, 2010.

[36] P. W. Ballantine and R. J. Stephenson, "Help me, i'm fat! social support in online weight loss networks," Journal of Consumer Behavior, Volume 10, Issue 6, Pages 332-337, 2011.

[37] J. L. Locher, W. C. Yoels, D. Maurer, and J. van Ells, "Comfort foods: An exploratory journey into the social and emotional significance of food," Journal of Food and Foodways, 2005.

[38] P. J. Guo, J. Kim, and R. Rubin, "How video production affects student engagement: an empirical study of mooc videos," in Proceedings of the first ACM conference on Learning, pp. 41-50, ACM, 2014.

[39] qq news, "Golden Big Food Fighters Yuka, Mizijun, Banzz are Fake Eating?." https://new.qq.com/ omn/20190507/20190507A0 9U07 . html, 2019.

[40] A. M. Barbarin, L. R. Saslow, M. S. Ackerman, and T. C. Veinot, "Toward health information technology that supports overweight/obese women in addressing emotion- and stress-related eating," in Proceedings of the 2018 CHI Conference on Human Factors in Computing Systems, CHI '18, pp. 321:1-321:14, ACM, 2018.

[41] W. Severin and J. Tankard, Communication theories: Origins, methods, and uses in the mass media. Longman, 1997.

[42] E. Katz, "Mass Communications Research and the Study of Popular Culture: An Editorial Note on a Possible Future for this Journal," Departmental Papers (ASC): 1-6, 1959.

[43] M. Levy and W. Sven, "The concept of audience activity," Media Gratifications Research: Current Perspectives: 109-122, 1985.

[44] J. C. Tang, G. Venolia, and K. M. Inkpen, "Meerkat and periscope: I stream, you stream, apps stream for live streams," in Proceedings of the CHI Conference on Human Factors in Computing Systems, pp. 4770-4780, ACM, 2016.

[45] Huaxia, "Eating and Chinese Culture." http: / / www . huaxia.com/zk/wh/00095878.html, 2003.

[46] Q. Mei, ““eating” in china,” China Plus, 2014.

[47] G. Ma, "Food, eating behavior, and culture in Chinese society," Journal of Ethnic Foods, Volume 2, Issue 4, Pages 195-199, 2015.

[48] L. C. Koo, "The use of food to treat and prevent disease in chinese culture," Social Science \& Medicine, vol. 18, issue 9, Pages 757-766, 1984.

[49] kknews, "Do you Like Watching Eating Shows? Are you Concerned about the Streamers' Health?." https:// kknews.cc/news/l6vrk4g.html, 2017. 